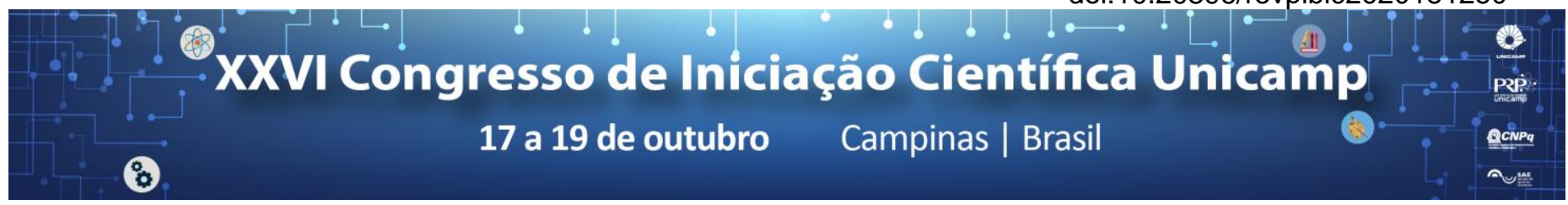

\title{
Análise de Classificadores para Interfaces Cérebro-Computador
}

\author{
Silvia Mosquera Santos*, Romis Attux.
}

\section{Resumo}

Uma Interface Cérebro-Computador é um meio de comunicação direto entre o cérebro e um dispositivo externo, muito utilizado em engenharia de reabilitação, pois pode auxiliar pacientes que tem funções do sistema neural comprometidas. A operação dessas interfaces abrange etapas de pré-processamento, extração de características e classificação. Neste trabalho, lidaremos com a última fase, realizando uma análise comparativa entre classificadores lineares e não-lineares no âmbito do paradigma de imaginação de movimento.

\section{Palavras-chave:}

Interface cérebro-computador, imaginação de movimento, aprendizado de máquina.

\section{Introdução}

Uma Interface Cérebro-Computador $(\mathrm{BCl}$, do inglês braincomputer interface) é um sistema de comunicação baseado em algum tipo de sinal cerebral. A escolha mais usual é a de sinais provenientes de eletroencefalografia (EEG).

Há três paradigmas principais em BCI: SSVEP, P300 e imaginação de movimento. No projeto, optamos pela interface baseada em imaginação de movimento. Após a aquisição do sinal, é necessário extrair ruídos/interferentes e eliminar as faixas de sinal biológico que são desinteressantes para o estudo. A partir dos atributos extraídos, é possível fazer a classificação dos comandos obtidos, que permite o treinamento da máquina e seu uso. A classificação pode se basear em diversos modelos matemáticos. Em nosso estudo, tivemos como foco os classificadores não-lineares, em especial a máquina de vetores-suporte (ou SVM, do inglês support vector machine) com funções de kernel gaussianas e as redes neurais do tipo perceptron de múltiplas camadas.

\section{Resultados e Discussão}

Escolhemos, na base de dados construída pelo grupo de pesquisa, os dados de um indivíduo que realizou imaginação de movimento da mão direita e da mão esquerda.

Utilizamos, como estruturas não-lineares, as SVMs e as redes neurais do tipo perceptron de múltiplas camadas. As SVMs são baseadas na noção de maximização da margem de classificação. As redes neurais são inspiradas pela estrutura do sistema nervoso, originando modelos matemáticos com parâmetros livres que são ajustados num processo de treinamento.

Todas a implementações foram feitas em MATLAB, e toolboxes foram usados na implementação da SVM e da rede neural. Utilizaram-se SVMs lineares e baseadas em kernel gaussiano. Também foi utilizado um classificador linear baseado em mínimos quadrados.

Os atributos utilizados foram valores da densidade espectral de potência em três faixas $(8-12 \mathrm{~Hz}, 13-$ $17 \mathrm{~Hz}, 18-22 \mathrm{~Hz}$ ) para os 16 eletrodos. Realizou-se um pré-processamento baseado em média comum.

Os dados foram divididos num conjunto de treinamento com aproximadamente $70 \%$ das amostras e num conjunto de validação de $30 \%$ de amostras (que fez o papel de conjunto de teste).
Em cada teste, foram realizadas vinte execuções, e podemos ver as taxas de erro médias dos quatro classificadores na tabela abaixo.

Tabela 1. Desempenho médio dos classificadores.

\begin{tabular}{|l|c|c|}
\hline Classificador & Erro Médio & Desvio Padrão \\
\hline Lin. Min. Quadrados & $19,1 \%$ & $6,8 \%$ \\
\hline SVM Linear & $20,0 \%$ & $6,0 \%$ \\
\hline SVM Não-linear & $17,9 \%$ & $8,8 \%$ \\
\hline Rede Neural & $15,7 \%$ & $13,1 \%$ \\
\hline
\end{tabular}

\section{Conclusões}

Tendo em vista a complexidade do problema estudado, era esperado que os classificadores não-lineares tivessem um desempenho melhor que os lineares, como foi possível observar na Tabela 1.

Entre os classificadores não-lineares, uma taxa de erro média inferior foi obtida com as redes neurais, embora o desempenho tenha sido próximo do desempenho da SVM, especialmente à luz dos desvios-padrão calculados.

Podemos concluir que o uso de classificadores nãolineares em BCls baseadas em imaginação de movimento é justificado.

\section{Agradecimentos}

Agradecemos o apoio financeiro do SAE/UNICAMP e do CNPq, bem como o apoio científico do laboratório DSPCom/FEEC.

G. Pfurtscheller, C. Neuper, Motor Imagery and Direct Brain-Computer Communication, Proc IEEE, v. 89, n.7, p. 1123-34, 2001.

J. R Wolpaw, N. Birbaumer, D. J. McFarland, G. Pfurtscheller e T. M Vaughan, Brain-computer interfaces for communication and control. Clinical Neurophysiology, v. 113, n.6, p. 767-791, 2002.

R. Yang, Signal processing for a brain computer interface, 2010. 